\title{
Potential of Candida glabrata from ragi as a bioethanol producer using selected carbohydrate substrates
}

\author{
MICKY VINCENT", QUEENTETY JOHNNY, DAYANG SALWANI AWANG ADENI, NURASHIKIN SUHAILI \\ Faculty of Resource Science and Technology, Universiti Malaysia Sarawak. 94300 Kota Samarahan, Sarawak, Malaysia. \\ Tel.: +60-825-82985, Fax.: +60-825-83160, `email: vmicky@unimas.my
}

Manuscript received: 16 September 2020. Revision accepted: 1 December 2020.

\begin{abstract}
Vincent M, Johnny Q, Adeni DSA, Suhaili N. 2021. Potential of Candida glabrata from ragi as a bioethanol producer using selected carbohydrate substrates. Nusantara Bioscience 13: 1-10. The flexibility and efficiency of fermenting microorganisms to convert substrates to ethanol are important factors in achieving high bioethanol yields during ethanolic fermentation. In this study, Candida glabrata, a common yeast found in fermented food, was evaluated in terms of its capability to produce ethanol using different types of carbohydrates, which included simple saccharides (glucose, maltose, sucrose), polysaccharides (starch and cellulose) and complex carbohydrates (total sago effluent, TSE). Our results indicated that $C$. glabrata was able to efficiently produce ethanol from glucose at 79.84\% TEY (Theoretical Ethanol Yield). The ethanol production from sucrose was low, which was only $6.44 \%$ TEY, while no ethanol was produced from maltose. Meanwhile, for complex carbohydrate substrates such as starch and cellulose, ethanol was produced only when supplementary enzymes were introduced. Simultaneous Saccharification and Fermentation (SSF) of starch dosed with amylases resulted in an ethanol yield of 55.08\% TEY, whilst SSF of cellulose dosed with cellulases yielded a TEY of 31.41\%. When SSF was performed on TSE dosed with amylases and cellulases, the highest ethanol production was recorded within $24 \mathrm{~h}$, with a yield of $23.36 \%$ TEY. Lactic acid and acetic acid were found to be at minimal levels throughout the fermentation period, indicating an efficient ethanol conversion. A notable increase in C. glabrata biomass was observed in cultures fed with glucose, starch (with supplementary amylases), and TSE (with supplementary amylases and cellulases). The current study indicates that $C$. glabrata can be used for bioethanol production from glucose, polysaccharides, and complex starchy lignocellulosic substrates such as TSE via SSF.
\end{abstract}

Keywords: Bioethanol, Candida glabrata, Metroxylon sagu, simultaneous saccharification and fermentation, total sago effluent

\section{INTRODUCTION}

The interest in producing renewable fuels has increased tremendously over recent years due to the instabilities of fossil fuel supplies and increasing global demands (Wei et al. 2015; Wong and Vincent 2019; Mohammad et al. 2020). Alternative liquid biofuel, such as bioethanol, is seen as the current choice of such renewable fuel to supplement and substitute petroleum-based fuel, due to its sustainability and carbon dioxide neutrality (Vincent et al. 2015; Hung et al. 2018). Compared to conventional gasoline, bioethanol is highly attractive as it offers cleaner combustion that is friendlier towards the environment. Economically, the bioethanol production and supply chain are also desirable as it creates many jobs and financial opportunities for both urban and rural areas (Ştefănescu-Mihăilă 2016).

In mass bioethanol production, substrate selection plays a major role. It is one of the main cost factors for the ethanol industry (Vincent et al. 2015). There are currently many feedstock sources that are used as substrates for bioethanol production (Techaparin et al. 2017; Ahorsu et al. 2018; Mohammad et al. 2020). When substrates such as lignocellulosic biomass are used to produce bioethanol, this type of bioethanol is termed as second-generation bioethanol (Zhang et al. 2016). It is projected that in the future, second-generation bioethanol will replace firstgeneration bioethanol, which is mostly produced from food-based materials, because of its low cost and feedstock abundance (Vincent et al. 2015; Ştefănescu-Mihăilă 2016). In bioethanol production, the typical bioprocess engaged is Simultaneous Saccharification and Fermentation (SSF) as this procedure offers higher reaction rates, higher yields, and greater ethanol concentrations compared to its closest counterparts such as Separate Hydrolysis and Fermentation.

The efficiency of ethanol production is also influenced by the species of microorganisms used. The desired microorganism should be robust and capable of converting substrates to ethanol effectively. The most common examples of ethanol producers are Saccharomyces cerevisiae, Zymomonas mobilis and Fusarium oxysporum (Ali et al. 2016; Vincent et al. 2018; Mohammad et al. 2020). Among these, S. cerevisiae has been mostly used in alcoholic fermentation due to its ethanol productivity. However, this particular species has several limitations. For example, poor stress tolerance and incapability to ferment xylose and arabinose, the main sugars released from hemicelluloses. Therefore, several genetic engineering studies to improve sugar utilization, ethanol production, and other applications have been explored (Carrasco et al. 2013; Pagliardini et al. 2013; Wong and Vincent 2019). Another approach is to search for new fermenting yeasts that may perform better or are more flexible than $S$. cerevisiae (Vincent et al. 2018).

Another yeast species that has similar characteristics to $S$. cerevisiae is Candida glabrata, which can be commonly 
found in fermented foods (Tsuyoshi et al. 2005) and starters, such as ragi, a traditional fermented food starter (Kofli and Davaon 2010; Hajar et al. 2012; Vincent et al. 2018). In this study, C. glabrata was isolated from the samples of ragi in Sarawak and was identified by using PCR and commercial identification kit. According to Kwon-Chung and Bennett (1992), C. glabrata was firstly classified under the genus Torulopsis due to its lack of pseudohypha production but in 1978 , it was confirmed that the ability to produce pseudohyphae was not a reliable distinguishing factor for members of the genus Candida; and thus it was classified as a member of Candida genus, along with over 200 species. The $C$. glabrata cell size was reported to be small compared to other Candida species and is in the range of 1 to $4 \mu \mathrm{m}$ (Fidel et al. 1999). In terms of ethanol production, C. glabrata is reported to be suitable for bioethanol fermentation as it possesses higher stress tolerance to acid and high temperatures in addition to impressive ethanol conversion capabilities (Watanabe et al. 2010). According to Merico et al. (2007), C. glabrata was reported to yield high ethanol percentages when grown under anaerobic conditions. Furthermore, C. glabrata is suitable for SSF since the optimum temperature for amylolytic and cellulolytic activities is above $40^{\circ} \mathrm{C}$.

Presently, limited information is available in the systematic studies of the ethanolic fermentation involving C. glabrata, especially when biomass is used as substrates. Biomass such as total sago effluent (TSE) can be found abundantly in Sarawak, Malaysia. TSE is a waste or residue from sago (Metroxylon sagu) industries that are usually disposed of into nearby rivers. According to Vincent et al. (2020), about 7 tons of TSE is discharged into the rivers per day from typical sago starch factories. This waste needs to be handled properly to avoid water pollution (Mohammad et al. 2020). TSE consists of sago hydrolysate, which is the liquid part while the solid component is called sago hampas. It is reported to contain high amount of lignocellulosic materials, which can be found in the solid sago hampas, making it suitable to be used as a substrate for bioethanol production (Hung et al. 2018). The hydrolysate can also contribute to bioethanol production as it contains starch that can be converted into fermentable sugars (Vincent et al. 2015). Therefore, the main objective of this study is to investigate the abilities of C. glabrata in producing ethanol from a variety of carbohydrates, ranging from common simple carbohydrates (glucose - monosaccharide, sucrose, and maltose disaccharides) to polymeric carbohydrates (starch and cellulose) and a complex carbohydrate mixture (total sago effluent).

\section{MATERIALS AND METHODS}

\section{Experimental setup}

Figure 1 shows an overview of the experimental procedures in this study.

\section{Collection of total sago effluent}

TSE was collected from Herdsen Sago Mill Sdn Bhd in Pusa, Sarawak (Figure 2). The TSE samples were stored at $-20{ }^{\circ} \mathrm{C}$ prior to its usage.

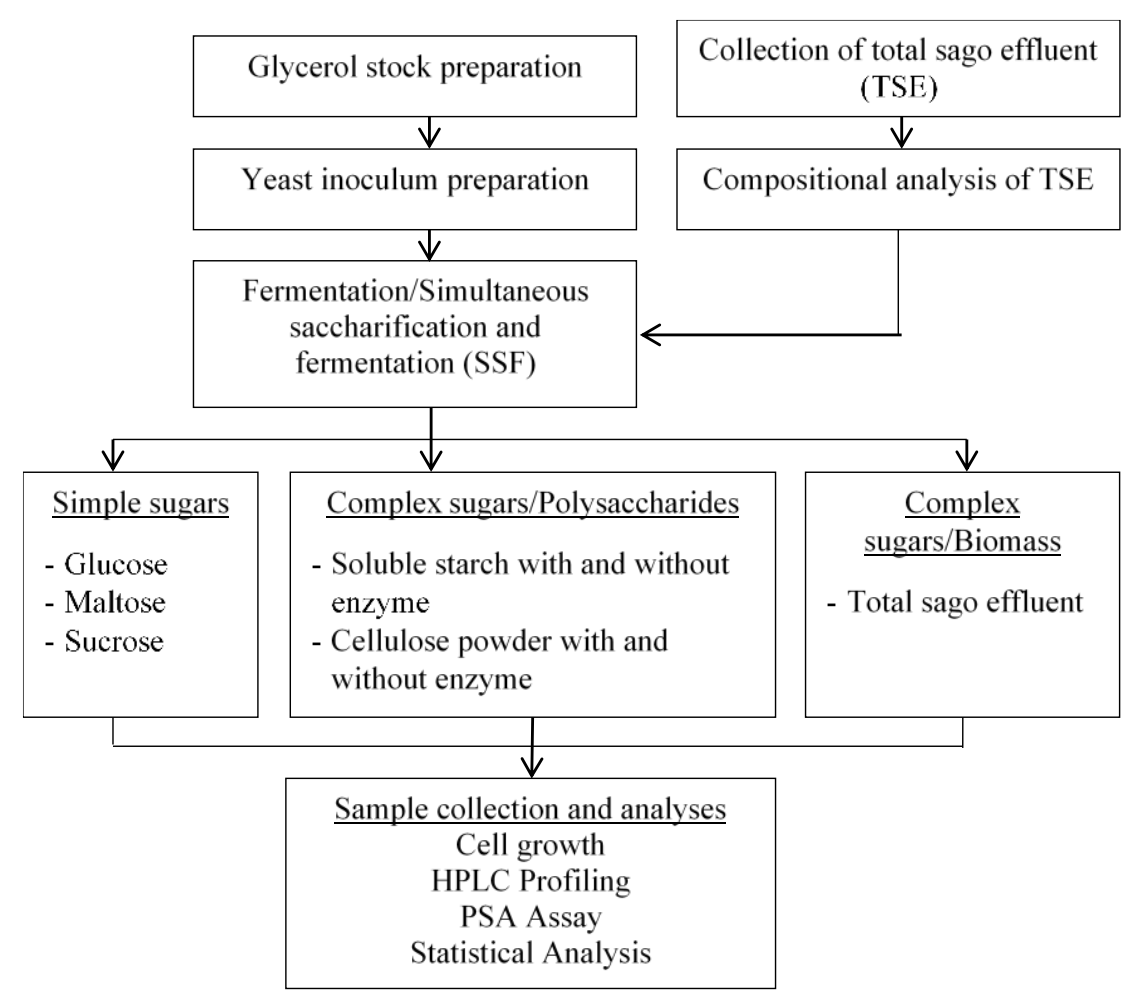

Figure 1. Overall experimental setup 

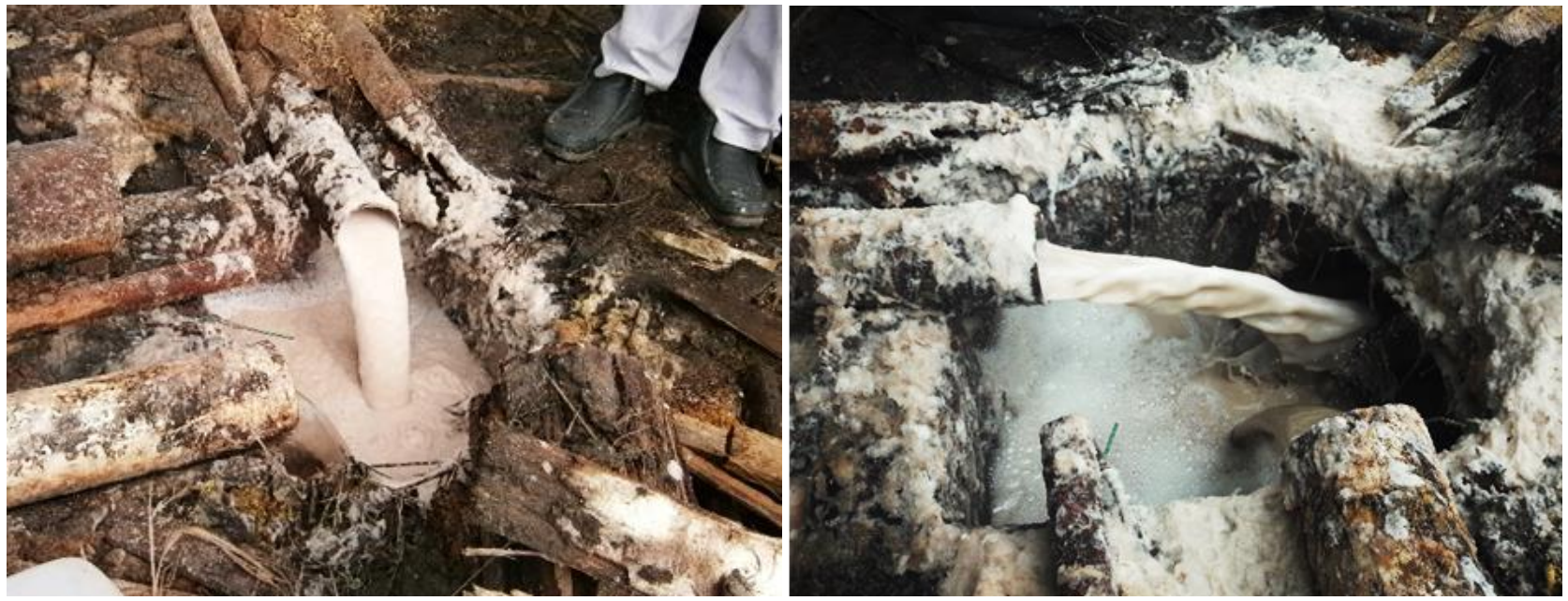

Figure 2. Total sago effluent (TSE) released from the sago mill in Pusa, Sarawak, Malaysia

\section{Characterization of sago hampas}

The moisture content of TSE sample was determined by measuring the weight loss from the initial weight after oven-drying (Shel Lab, USA) at $105^{\circ} \mathrm{C}$ for 3 days. Prior to the characterization process, the TSE was oven-dried before it was ground to fine powder. The powdered samples were subjected to starch and fiber analysis by using the Phenol-Sulphuric Acid assay (PSA), Acid detergent Fiber (ADF), Neutral Detergent Fiber (NDF), and Klason Lignin Determination (Goering and van Soest 1970). The ash content was determined using furnace incineration, where the sample was subjected to dry ashing at $550^{\circ} \mathrm{C}$ for 6 hours in an ashing muffle furnace $(\mathrm{KC}$, 40/13. ThermConcept, Germany).

\section{Glycerol stock preparation}

The $C$. glabrata strain used in this study was isolated from samples of ragi, collected from Kuching, Sarawak (Malaysia) (Vincent et al. 2018). Isolation of yeast single colonies was carried out on Rose Bengal Chloramphenicol Agar (RBDC) (Hi Media, India) and the single colonies obtained were grown in YM broth (Sigma, USA) by shaking at $150 \mathrm{rpm}$ (NB-101MT Multi Shaker, N-Biotek, Korea) at ambient temperature. For long-term storage, the stock culture was prepared by mixing culture medium with $20 \%$ (v/v) glycerol (R\&M Marketing, UK) and were stored at $-20^{\circ} \mathrm{C}$ for preservation.

\section{Candida glabrata inoculum preparation}

For C. glabrata inoculum preparation, the cultures were taken from the glycerol stocks. The cultures were grown overnight in YM broth at ambient temperature with constant shaking at $150 \mathrm{rpm}$. The cultures were then centrifuged (BK1032J Low-Speed Centrifuge, Biobase, China) for 6 min at $4500 \mathrm{rpm}$. The resulting C. glabrata cell pellets were used as inocula for fermentations in this work.

\section{Fermentation -using glucose, maltose and sucrose}

Fermentation medium was prepared in $500 \mathrm{~mL}$ Schott bottles containing $150 \mathrm{~mL}$ of mixed solution of $1.5 \mathrm{~g} / \mathrm{L}$ of yeast extract (Bacto, USA), $3.0 \mathrm{~g} / \mathrm{L}$ of bacteriological peptone (Bendosen Laboratory Chemicals, Malaysia) and $5 \%(\mathrm{w} / \mathrm{v})$ of either glucose (R\&M Chemical, United Kingdom), maltose (R\&M Chemical, United Kingdom) or sucrose (Bendosen Laboratory Chemicals, Malaysia) in $0.05 \mathrm{M}$ citrate buffer, $\mathrm{pH}$ 5.0. The $\mathrm{pH}$ of the media was adjusted to the optimum $\mathrm{pH}$ level for fermentation at 4.8, before it was autoclaved (Model No. 25X Electric Pressure Steam Sterilizer, All American, United State) for 15 min at $121^{\circ} \mathrm{C}$. Prior to the fermentation, the harvested cells, which were in the range of $1.29 \times 10^{8}$ cells $/ \mathrm{mL}$ to $2.86 \times 10^{8}$ cells $/ \mathrm{mL}$ were added aseptically into the sterilized fermentation media. Fermentations were carried out, anaerobically for 5 days, at ambient temperature with a constant shaking of $150 \mathrm{rpm}$. For each type of sugar, the fermentations were done in triplicates $(n=3)$.

\section{Fermentation -using starch and cellulose}

The two sets of media consisting of polysaccharides namely 5\% (w/v) starch (Bendosen Laboratory Chemicals, Malaysia) and 5\% (w/v) cellulose (Nacalai Tesque, Japan) were prepared separately. After the $\mathrm{pH}$ adjustment to 4.8 , the media were autoclaved in order to sterilize and also to gelatinize the starch. Next, the harvested $C$. glabrata cells and $75 \mu \mathrm{L}$ of each amylase (Sunson, China), $\alpha$-amylase (EC.3.2.1.1) and glucoamylase (EC.3.2.1.3) were added into the sterile starch solution, while $2.0 \mathrm{~mL}$ of cellulase (50 FPU) (Sunson, China) was added into the sterile cellulose solution. Cellulase enzymes used consisted of acid cellulase, beta-glucosidase, and xylanase. Another set of sterile starch and cellulose solution was prepared but no enzyme was added to those media. The fermentations were conducted under the same conditions of the fermentation with simple sugars.

\section{Fermentation - using total sago effluent (TSE)}

TSE fermentation medium was prepared by mixing 1.5 $\mathrm{g} / \mathrm{L}$ yeast extract, $3.0 \mathrm{~g} / \mathrm{L}$ peptone, and $0.05 \mathrm{M}$ citrate buffer, with $\mathrm{pH}$ of 5 , in a $500 \mathrm{~mL}$ Schott bottle and the solution was topped up to $150 \mathrm{~mL}$ with TSE. Following the $\mathrm{pH}$ adjustment 
to 4.8 and sterilization, about $75 \mu \mathrm{L}$ of each amylase ( $\alpha$ amylase and glucoamylase) and $2.0 \mathrm{~mL}$ of cellulase were added in order to start the SSF of TSE. SSF was done in triplicates $(n=3)$ according to the same conditions as the fermentation described earlier.

\section{Sample collection and Candida glabrata cell count}

About $1.5 \mathrm{~mL}$ of culture broth was pipetted out at 0,6 , 12, 24, 36, 48, 72, 96 and $120 \mathrm{~h}$ during the fermentation. Prior to HPLC analyses, cell counting was performed using hemocytometer (Optik Labor, United Kingdom) and the viable cells were observed under a light microscope after methylene blue staining. The remaining supernatant was centrifuged (WiseSpin CF-10 High-Performance Microcentrifuge Set, Daihan Scientific, Korea) at 13,500 rpm for $3 \mathrm{~min}$ and was filtered through a $0.45 \mu \mathrm{m}$ nylon membrane filter (Whatman, NJ, USA) to eliminate any solid residues. The filtrate was used for phenol-sulfuric acid assay (PSA) and High-Performance Liquid Chromatography (HPLC) analyses.

\section{Phenol-sulfuric acid assay (PSA)}

Total carbohydrate content of the samples was determined based on PSA assay. The assay was performed by measuring the optical density of the samples at $490 \mathrm{~nm}$ using a spectrophotometer (SP-880 Metertech, Taiwan). The amount of total carbohydrate present in the samples was determined based on a standard curve, which was plotted prior to the assay.

\section{Analytical analysis}

Quantification of ethanol, sugars, lactic acid and acetic acid was performed using High-Performance Liquid Chromatography (HPLC) (Waters 2695 Separations Module, Alliance HPLC System, United States) The HPLC system was equipped with a column heater, refractive index detector (2414 RI Detector) and computer controller. The protocols for separation and analyses of ethanol and other fermentation constituents were according to Vincent et al. (2015). Theoretical Ethanol Yield (TEY) of each substrate was determined based on ethanol produced and was calculated as follows:

$\mathrm{TEY}=($ Ethanol produced $(\mathrm{g} / \mathrm{L}) /$ conversion factor $\mathrm{x}$ initial concentration of sugar) $\mathrm{x} 100$

Where,

Conversion factor for sugar to ethanol $=0.511$

Conversion factor for biomass to sugar $=1.1$

\section{Statistical analysis}

Error bars were determined based on the standard deviation from the mean value of triplicate experiments. The data was statistically analyzed using One-way Analysis of Variance (ANOVA) and Tukey's Post Hoc test (SPSS Statistics Software version 22), and the differences were considered significant if $p<0.05$.

\section{RESULTS AND DISCUSSION}

\section{Candida glabrata cell growth using different carbohydrate feedstock}

In the current study, the ability of $C$. glabrata, isolated from local wine starter (ragi), in utilizing and fermenting different carbohydrates (mono-, di-, polysaccharides and complex mixture), represented by glucose, sucrose, maltose, starch, cellulose, and total sago effluent (TSE), to bioethanol and other byproducts were examined. Similar to other common yeasts, $C$. glabrata utilizes these different classes of carbohydrates differently, either for primary cell growth or for conversion to other secondary metabolites, alcohols, or organic acids.

A rapid and good specific growth rate is crucial for efficient fermentation and high yield of ethanol (Chang et al. 2018). For this reason, the cell population growth of $C$. glabrata in all substrates was monitored in order to gauge its growth profile. Based on the results from Figure 3, $C$. glabrata cells were propagating rapidly in the first $12 \mathrm{~h}$ in all fermentations. However, a notable increase in the first 6 $\mathrm{h}$ was only observed in fermentations employing glucose, starch with enzyme and TSE while the growth in other fermentations was relatively slower. After $48 \mathrm{~h}$, a gradual decline in cell concentration was observed in all fermentations, due to substrate limitation and/or ethanol toxicity. The same observations were reported in studies elsewhere (Jönsson et al. 2013). Throughout the fermentation period, the trend of change of sugar uptake and alcohol production profiles was found to coincide with the logarithmic phase of the growth profile.

\section{Ethanol production from glucose, maltose and sucrose}

Figure 4 shows the time course of ethanol production during the fermentation by $C$. glabrata using different carbon sources. The ethanol production in fermentations using glucose increased sharply from 0 to $48 \mathrm{~h}$, with the maximum production of $20.40 \mathrm{~g} / \mathrm{L}$ (79.84\% TEY) achieved at $72 \mathrm{~h}$. After $72 \mathrm{~h}$, the production of ethanol decreased slowly over time. At the later stage of fermentation, the ethanol concentration decreased in most of the fermentation because the yeast required energy to maintain growth. According to Li et al. (2017), the yeast consumed some ethanol to obtain energy due to the small amount of residual sugars in the media. From Figure 4, low ethanol yield was observed in the fermentation using sucrose, with the peak production of only $1.64 \mathrm{~g} / \mathrm{L}$ at $6 \mathrm{~h}$. On the other hand, no ethanol was detected in fermentations using maltose throughout the 5 days of incubation. This showed that $C$. glabrata does not produce particular enzyme to break down maltose. In the meantime, only low ethanol produced in fermentations using sucrose, which was probably caused by certain conditions such as concentration of starting materials, $\mathrm{pH}$, or temperature during the fermentation. 


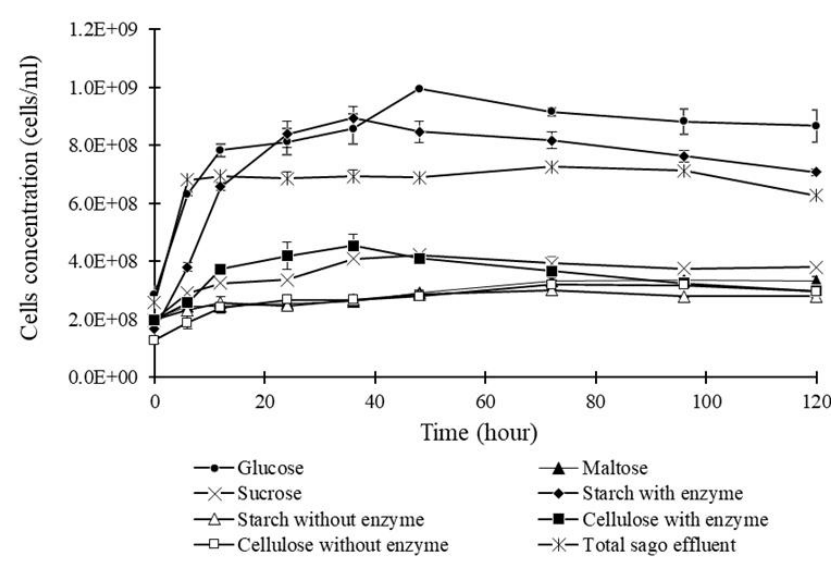

Figure 3. Time course of cell concentration during bioethanol fermentation by $C$. glabrata using different carbon sources. The data points represent the average of three independent experiments $(\mathrm{n}=3)$

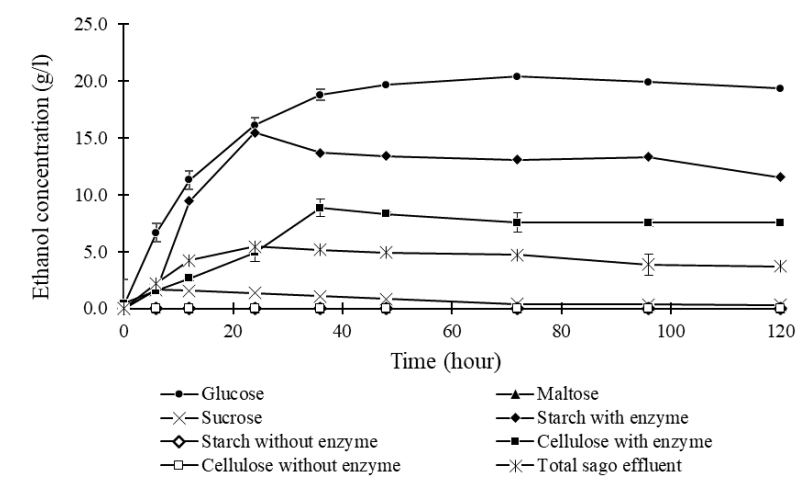

Figure 4. Time course of ethanol concentration during bioethanol fermentation by $C$. glabrata using different carbon sources. The data points represent the average of three independent experiments $(n=3)$

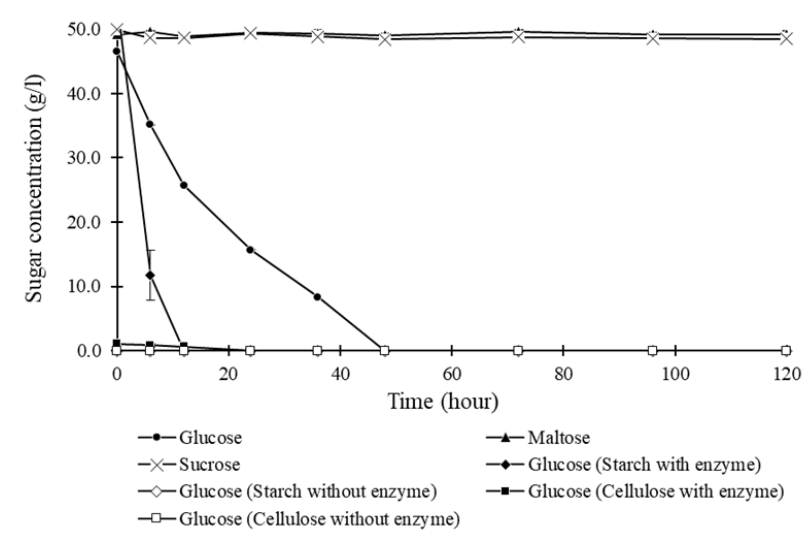

Figure 5. Time course of sugar concentration during bioethanol fermentation by $C$. glabrata using different carbon sources (simple sugars and complex sugars). The data points represent the average of three independent experiments $(n=3)$
The high efficiency of conversion of glucose to ethanol by $C$. glabrata was also documented previously by Barnett et al. (2000). Our study has shown that $C$. glabrata was capable of fermenting glucose efficiently. According to Mosier (2005), hexoses such as glucose can be fermented by most microorganisms species, especially yeasts. Glucose is also considered the best substrate for growing yeast cells and also ethanol fermentation (Ruriani et al. 2012). Conversion of glucose to ethanol at $79.84 \%$ of the theoretical value obtained in this work is considered high yield. The maximum yield is usually lower than $90 \%$ because it is usually limited by nutrients or substrates used to synthesize biomass and maintain the reactions. Another similar study conducted by Techaparin et al. (2017) on ethanol production from glucose by $C$. glabrata reported only a $42 \%$ conversion. By comparison, the $C$. glabrata strain used in this work showed higher efficiency of ethanol production, which renders its practicality for industrial applications.

Figure 5 shows the profile of sugar consumption during fermentation by $C$. glabrata using different substrates. The profile depicts a steady decrease of glucose concentration during the 48-hour incubation. However, the concentration of maltose and sucrose remained unchanged at approximately $48.0 \mathrm{~g} / \mathrm{L}$ throughout the fermentation period. This observation is in agreement with the reports on the extremely narrow carbon utilization range of $C$. glabrata when compared to other yeasts (Turner and Butler 2014).

\section{Simultaneous saccharification and fermentation (SSF) of starch, cellulose, and total sago effluent (TSE)}

The ability of $C$. glabrata to saccharify starch, cellulose, and TSE for ethanol production was also evaluated in this work. Both starch and cellulose are classified as glucose-based polymers, with the latter more abundant in nature. However, these two carbohydrates differ in the orientation of the linkages between the glucose subunits (Jacques et al. 2003). As shown in Figure 5, the initial glucose concentration in fermentation medium containing starch was completely depleted after $12 \mathrm{~h}$ of fermentation, which was in line with the increase of ethanol starting at $6 \mathrm{~h}$. The maximum concentration of ethanol $(15.23 \mathrm{~g} / \mathrm{L})$ was achieved at $24 \mathrm{~h}$. On the other hand, no glucose was detected in the fermentation medium containing starch when the supplementary enzymes were not added.

The results indicated that supplementary amylases are important in the alcoholic fermentation of C. glabrata as no ethanol was produced in the absence of the enzymes. These results can also be correlated with the sugar consumption profile (Figure 5) where glucose was only detected in media that was dosed with amylases. The conversion of starch to glucose occurred most efficiently on the first day of SSF as the maximum production of ethanol was recorded at $24 \mathrm{~h}$, along with the depletion of glucose in the fermentation media. Our findings suggest that $C$. glabrata does not produce amylolytic enzymes to breakdown starch in the fermentation broth.

When cellulose powder was used as a carbon source, ethanol was only detected in the medium containing 
supplementary cellulases. The ethanol concentration increased gradually over the $36 \mathrm{~h}$ of fermentation, peaking at about $8.83 \mathrm{~g} / \mathrm{L}$, as shown in Figure 4. After that, the ethanol yield started to remain constant until the end of the SSF period. On the contrary, in the absence of supplementary enzymes, no ethanol yield was recorded throughout the SSF period, as shown in Figure 4. This outcome indicates that cellulases are crucial for the conversion of cellulose to ethanol, as supported by the findings by Fox et al. (2012) where the cellulase action on the insoluble cellulosic substrates is modeled as a heterogenous biocatalytic reaction. The reaction involves endo- and exocellulases that either interact directly with soluble cello-oligosaccharides or form complexes with insoluble cellulose chains. Cello-oligosaccharides are saccharides that consist of 2 to 6 glucose by $\beta$-1-4-linkages, containing mainly cellobiose (Zhao et al. 2009). This study further confirms the inability of $C$. glabrata to breakdown cellulose and requires extracellular cellulases to convert cellulose into fermentable sugar.

SSF was also performed on TSE. The compositional analyses of TSE prior to SSF are presented in Table 1 and Table 2. The TSE used in the current study consisted of sago effluent hydrolysate (water component) and sago hampas (solid component), with $97.14 \%$ was the water component as shown in Table 1. Approximately $2.23 \%$ of the hydrolysate was starch, which can be converted to fermentable sugar through enzymatic hydrolysis. Further analysis of sago hampas was carried out to determine the exact amount of lignocellulosic contents. As outlined in Table 2, dried sago hampas used in this study contained $52.03 \%$ starch, $27.82 \%$ cellulose, $5.32 \%$ hemicellulose and $3 \%$ lignin. The results obtained in this work are comparable to a previous report by Hung et al. (2018), where sago hampas were reported to contain $55.4 \%$ starch, $23.6 \%$ cellulose, $9.1 \%$ hemicellulose, and $4.0 \%$ lignin. Furthermore, the starch content recorded in this study, which was in the range of $30 \%-50 \%$ was comparable with that reported by Awg-Adeni et al. (2010). The variation of lignocellulosic composition can be associated with the difference in the sago species, growth conditions and maturity (Kim et al. 2010; Tye et al. 2011). The amount of cellulose and hemicellulose in biomass is the key in biofuel production, as they are convertible into bioethanol (Malherbe and Cloete 2003).

Figure 6 shows the profile of total soluble carbohydrates and sugars released during SSF of TSE. The initial total carbohydrate concentration was recorded at $20.57 \mathrm{~g} / \mathrm{L}$. At $6 \mathrm{~h}$, the total carbohydrate content declined steeply to $4.98 \mathrm{~g} / \mathrm{L}$, giving a total reduction of approximately $75 \%$. At $12 \mathrm{~h}$, the concentration decreased further to $4.02 \mathrm{~g} / \mathrm{L}$ and remained relatively constant until the end of the SSF period. The initial glucose concentration was $16.47 \mathrm{~g} / \mathrm{L}$ at $0 \mathrm{~h}$, before it decreased to $0.56 \mathrm{~g} / \mathrm{L}$ at $6 \mathrm{~h}$ and became completely depleted after $12 \mathrm{~h}$. For cellobiose, the initial concentration was $4.32 \mathrm{~g} / \mathrm{L}$ and it decreased to $1.62 \mathrm{~g} / \mathrm{L}$ and became plateau until the end of the incubation. Another wood sugar, arabinose was also detected in the TSE samples with the concentrations fluctuated slightly between 0.8 and $0.9 \mathrm{~g} / \mathrm{L}$, before peaking at $1.10 \mathrm{~g} / \mathrm{L}$ at $120 \mathrm{~h}$. There was no xylose detected at the initial stage of SSF until at $12 \mathrm{~h}$ when a concentration of $0.19 \mathrm{~g} / \mathrm{L}$ was detected. The xylose concentration remained between 0.25 and $0.27 \mathrm{~g} / \mathrm{L}$ throughout the remaining SSF period. A trace amount of arabinose with a concentration of $0.40 \mathrm{~g} / \mathrm{L}$ was detected and the amount was found to remain constant throughout the incubation. Xylose and arabinose are the most abundant pentose sugars in hemicellulose (Bettiga et al. 2009). These sugars are released from xyloglucan, xylan, arabinan and arabinogalactan (substructures of pectin) from polysaccharides in plant cell (Battaglia et al. 2011).

Table 1. Compositional analysis of total sago effluent TSE comprising of sago hydrolysate and dried sago hampas.

\begin{tabular}{lll}
\hline Compositions & Amount $(\%)$ & \\
\hline $\begin{array}{l}\text { Sago hydrolysate } \\
\text { (water component) }\end{array}$ & Water & $94.91 \pm 0.09$ \\
& Free Starch & $2.23 \pm 0.86$ \\
& Starch & $1.49 \pm 1.11$ \\
& Cellulose & $0.79 \pm 1.23$ \\
Dried sago hampas & Hemicellulose & $0.15 \pm 2.00$ \\
(solid component) & Lignin & $0.09 \pm 0.09$ \\
& Ash & $0.06 \pm 0.06$ \\
& Others & $0.28 \pm 0.00$ \\
\hline
\end{tabular}

Table 2. Compositional analysis of dried sago hampas The percentages was based on dry weight, $\mathrm{n}=3$.

\begin{tabular}{ll}
\hline Compositions & \% w/w \\
\hline Starch & $52.03 \pm 1.11$ \\
Cellulose & $27.82 \pm 0.62$ \\
Hemicellulose & $5.32 \pm 0.96$ \\
Lignin & $3.00 \pm 0.05$ \\
Ash & $1.95 \pm 0.03$ \\
Others & $9.88 \pm 0.07$ \\
\hline
\end{tabular}

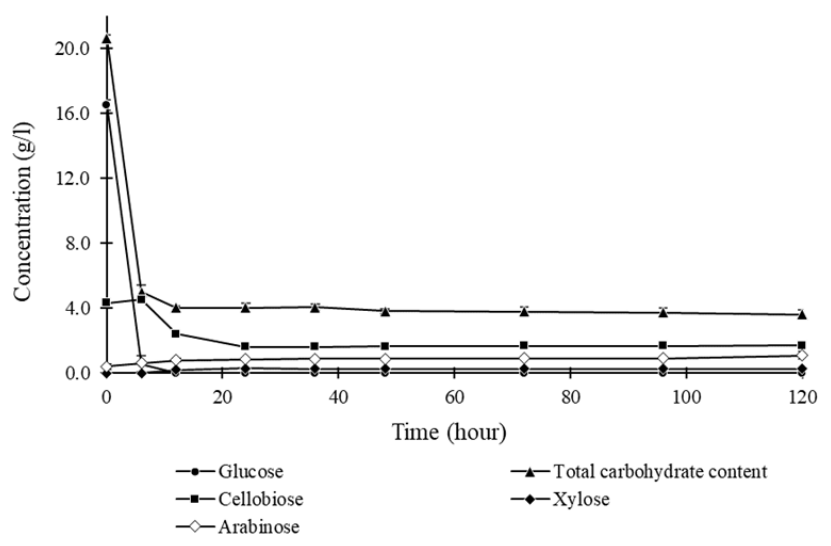

Figure 6. Time course of total carbohydrate content and sugar concentration (glucose, cellobiose, xylose, arabinose) during SSF of TSE. The data points represent the average of three independent experiments $(n=3)$. 
As shown in Figure 6, xylose was only detected at $12 \mathrm{~h}$ and the peak was found at $24 \mathrm{~h}$. This showed that the breakdown of hemicellulose only started to occur at $12 \mathrm{~h}$ and onwards. In contrast, a trace amount of arabinose was detected from the beginning until the end of SSF. The degradation of pectin during the autoclaving process of media preparation may have resulted in the accumulation of arabinose at this stage. The concentration of arabinose was found to increase during the first $12 \mathrm{~h}$, indicating the active breakdown of hemicellulose by xylanase into xylose and arabinose. After $24 \mathrm{~h}$, the concentration of xylose and arabinose remained constant until the end of SSF implying the inability of $C$. glabrata to utilize both sugars. This is in parallel with a study by Barnett et al. (2000) and Ruriani et al. (2012) that reported the selective fermentation of $C$. glabrata. The same studies further reported that yeast cells basically use monosaccharides for their growth, but only a few of the monosaccharide compounds such as glucose, galactose and mannose can be converted into ethanol. Pentose sugars (five-carbon sugars) such as xylose and arabinose, can only be fermented by a small number of wild microorganisms, often with a low ethanol yield (Mosier 2005).

A complete breakdown of cellulose into glucose involves extracellular cellulases. Cellobiose, a disaccharide, is usually the intermediate product. Based on our results, the highest concentration of cellobiose was found in the beginning of SSF indicating the enzymatic hydrolysis of cellulose into cellobiose. Subsequently, $\beta$ glucosidases, a part of cellulase enzymes will cleave cellobiose into 2 glucose units (Lynd et al. 2002). The depletion of cellobiose denotes the effective enzymatic activity in the fermentation broth. However, cellobiose was only detected in low concentrations, and this in turn resulted in a low yield of glucose.

Based on Figure 6, a steep decrease of total sugar content during the first $6 \mathrm{~h}$ indicated that the substrates present in the fermentation broth were rapidly fermented into ethanol by $C$. glabrata. The same observations were also reported by Hung et al. (2018) who stated that not all sugars can be converted to ethanol. In addition, the results obtained in this study showed the presence of other unknown hexose sugars in the fermentation broth besides glucose.

Ethanol was produced at the early stage of SSF, with a concentration of $2.22 \mathrm{~g} / \mathrm{L}$ recorded at $6 \mathrm{~h}$, as shown in Figure 4. The increase in ethanol yield is highly correlated with the steep decrease in glucose concentration. After the depletion of glucose at $6 \mathrm{~h}$, the ethanol concentration continued to increase until its maximum production at $24 \mathrm{~h}$. The highest ethanol concentration was $5.44 \mathrm{~g} / \mathrm{L}$. This corresponds to an estimated $21.25 \%$ TEY, which is significantly lower than that reported by Hung et al. (2018) (79.65\% TEY). The author reported a higher TEY because they used only sago hampas as substrate, while in this study, the mixture of sago effluent and sago hampas was used. Compared to sago hampas, TSE contains less lignocellulosic materials and thus produced less ethanol.

\section{Analyses of fermentation by-products - Lactic acid and acetic acid}

Figure 7 depicts the profile of lactic acid during fermentation by $C$. glabrata using different carbon sources. Lactic acid commonly comes from lactic acid bacteria (LAB). A sharp increase of lactic acid was observed in fermentations using glucose as a substrate with a peak of $3.71 \mathrm{~g} / \mathrm{L}$ at $24 \mathrm{~h}$, which was caused by the presence of LAB in the media throughout the fermentation. On the other hand, the lactic acid concentration was relatively low in fermentations that use other carbon sources.

Figure 8 illustrates the concentration of acetic acid during the fermentation by $C$. glabrata using different carbon sources. Overall, the level of acetic acid in all fermentations was recorded to be less than $0.5 \mathrm{~g} / \mathrm{L}$. Similar to lactic acid, acetic acid also comes from bacteria, acetic acid bacteria (AAB). A previous study stated that acetic acid also can be found in hydrolysates and it basically comes from acetyl side-chains in hemicellulose. According to Vincent et al. (2015), acetic acid is an important indicator of the efficiency of biomass hydrolysis where an increase in acetic acid concentration in the fermentation broth denotes a continuous degradation of the lignocellulosic components of TSE throughout the SSF period.

Although the presence of organic acids is common in typical fermentation systems, the concentrations of lactic acid and acetic acid must, however, be closely monitored to avoid a reduction in the ethanol production due to the changes in the $\mathrm{pH}$ of the fermentation media (Lin et al. 2012). According to Narendranath (2003), the presence of these acids in high concentrations can also be indicator of contamination, which could be caused by Lactobacilli. In this study, the overall concentrations of both lactic acid and acetic acid in the cultures were relatively low $(<0.5 \mathrm{~g} / \mathrm{L})$. This indicated that the fermentations were free from contaminations caused by bacteria, except for the media containing glucose.

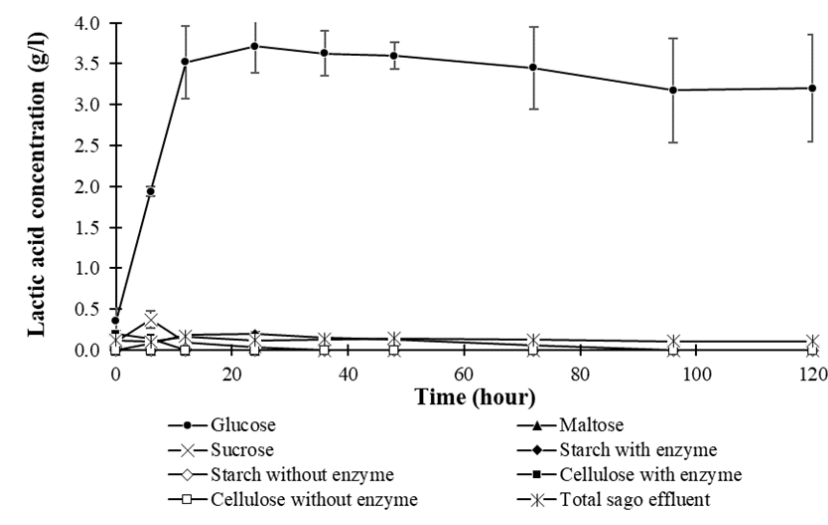

Figure 7. Time course of lactic acid concentration during bioethanol fermentation by $C$. glabrata using different carbon sources. The data points represent the average values of three independent experiments $(n=3)$. 


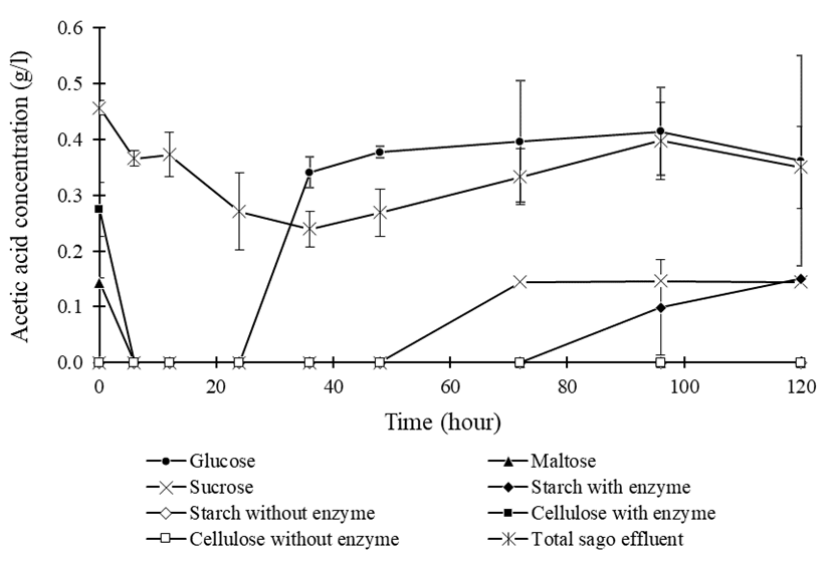

Figure 8. Time course of acetic acid concentration during bioethanol fermentation by $C$. glabrata using different carbon sources. The data points represent the average of three independent experiments $(\mathrm{n}=3)$

Table 3. Maximum ethanol production and yield achieved in fermentation by $C$. glabrata using different substrates.

\begin{tabular}{ll}
\hline Substrate & $\begin{array}{l}\text { Maximum production } \\
\text { of ethanol }(\mathbf{g} / \mathbf{L})\end{array}$ \\
\hline Glucose & $20.40 \pm 0.30$ \\
Maltose & $0.00 \pm 0.00$ \\
Sucrose & $1.64 \pm 0.08$ \\
Starch with enzyme & $15.23 \pm 2.11$ \\
Starch without enzyme & $0.00 \pm 0.00$ \\
Cellulose with enzyme & $8.83 \pm 0.76$ \\
Cellulose without enzyme & $0.00 \pm 0.09$ \\
Total sago effluent & $5.54 \pm 0.09$ \\
\hline
\end{tabular}

Note: *Data are mean of triplicates \pm S.D (Different superscript letters in the same column show significant differences, $p$-value < $0.05)$

Table 3 outlines the overall maximum ethanol production and yield achieved in fermentation by $C$. glabrata using different substrates. The highest ethanol production was recorded in fermentations using glucose as a substrate. A maximum ethanol concentration of $20.4 \mathrm{~g} / \mathrm{L}$ was produced, which corresponded to a theoretical yield of $79.84 \%$. This clearly showed that in comparison to other carbon sources examined in this study, glucose is the best substrate for ethanol production by C. glabrata. The second best substrate was found to be starch when it was supplemented with enzymes. The maximum ethanol concentration achieved was $15.23 \mathrm{~g} / \mathrm{L}$ and with a theoretical yield of $55.08 \%$. In contrast, there was no ethanol yielded in fermentations using maltose, starch, and cellulose. Among all substrates tested in this work, only glucose and sucrose were consumed by $C$. glabrata to produce ethanol. Meanwhile, it is observed that soluble starch and cellulose were consumed only with the aids of the supplementary enzymes, with the former gave a higher yield. As for the SSF of TSE, the maximum ethanol production was $5.44 \mathrm{~g} / \mathrm{L}(21.25 \% \mathrm{TEY})$. Although the ethanol concentration was relatively low compared to that achieved using other carbon sources, the results do reflect the ability of $C$. glabrata to grow on TSE. It is expected that higher yield of ethanol can be achieved upon further optimization of the SSF process.

In conclusion, the results from this study indicated that C. glabrata was capable to ferment glucose efficiently (79.84\% of theoretical yield), making it as compared to other common fermenting yeasts such as $S$. cerevisiae, which was reported to yield TEY of 40 to $49 \%$ when fermenting 4 to $5 \%$ (w/v) glucose (Govindaswamy and Sane 2010; Kumar et al. 2011). Although C. glabrata is incapable of fermenting other sugars such as xylose and arabinose as well as polysaccharides like starch and cellulose without the aid of supplementary amylases and cellulases, the strain does show a promising potential to be used for fermenting starchy industrial waste such as TSE.

\section{ACKNOWLEDGEMENTS}

This work was supported by the Tun Openg Sago Chair Grant [F07/TOC/1518/2016].
Experimental theoretical yield (\%)

$79.84 \pm 1.18 \mathrm{a}$

REFERENCES

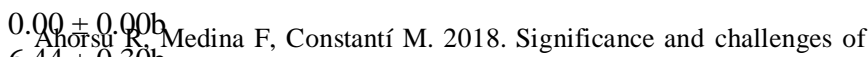
6.44 thlomas as a suitable feedstock for bioenergy and biochemical

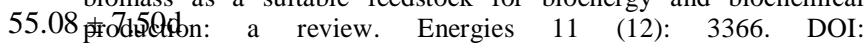
$0.00 \pm 0$. B)Bbon/en11123366.

31A4il \$S3. Nlegent B, Mullins E, Doohan FM. 2016. Fungal-mediated $0.00 \pm$ E. 90 bidated bioprocessing: The potential of Fusarium oxysporum for 21.25 the bgnocellulosic ethanol industry. AMB Express 6: 13. DOI: 10.1186/s13568-016-0185-0.

Awg-Adeni DS, Abd-Aziz S, Bujang K, Hasaan MA. 2010. Bioconversion of sago residues into value-added products. Afr $\mathrm{J}$ Biotechnol 9 (4): 2016-2021.

Barnett JA, Payne RW, Yaroww D. 2000. Yeasts: Characteristics and identification. Cambridge University Press, USA.

Battaglia E, Hansen SF, Leendertse A, Madrid S, Mulder H, Nikolaev I, de Vries RP. 2011. Regulation of pentose utilisation by AraR, but not $\mathrm{X} \operatorname{lnR}$, differs in Aspergillus nidulans and Aspergillus niger. Appl Microbiol Biotechnol 91 (2): 387-397.

Bettiga M, Bengtsson O, Hahn-Hagerdal B, Gorwa-Grauslund MF. 2009. Arabinose and xylose fermentation by recombinant Saccharomyces cerevisiae expressing a fungal pentose utilization pathway. Microb Cell Fact 8: 40-52.

Carrasco C, Baudel H, Roslander C, Galbe M, Lidén G. 2013. Fermentation of the straw material paja brava by the yeast Pichia stipitis in a simultaneous saccharification and fermentation process. $\mathrm{J}$ Sustain Bioenergy Syst 3: 99-106.

Chang YH, Chang KS, Chen CY, Hsu CL, Chang TC, Jang HD. 2018. Enhancement of the Efficiency of Bioethanol Production by Saccharomyces cerevisiae via Gradually Batch-Wise and Fed-Batch Increasing the Glucose Concentration. Ferment 4 (2): 45-57.

Fidel PL, Vazquez JA, Sobel JD. 1999. Candida glabrata: Review of Epidemiology, Pathogenesis, and Clinical Disease with Comparison to C. albicans. Clin Microbiol Rev 12 (1): 80-96.

Fox JM, Levine SE, Clark DS, Blanch HW. 2012. Initial- and processivecut products reveal cellobiohydrolase rate limitations and the role of companion enzymes. Biochem 51: 442-452.

Goering HK, van Soest PJ. 1970. Forage fiber analyses (apparatus, reagents, procedures, and some applications). Agriculture Handbook No. 379. United States Department of Agriculture, Washington, DC.

Govindaswamy S, Vane LM. 2010. Multi-stage continuous culture fermentation of glucose-xylose mixtures to fuel ethanol using genetically engineered Saccharomyces cerevisiae 424S. Bioresour Technol 101: 1277-1284. 
Hajar S, Noorhisham T, Nurina A. 2012. Short Technical Communication Yeast Identification from domestic ragi for food fermentation by PCR method. Int Food Res J 19: 775-777.

Hung CH, Adeni DSA, Johnny Q, Vincent M. 2018. Production of bioethanol from sago hampas via Simultaneous Saccharification and Fermentation (SSF). Nusantara Biosci 10 (4): 240-245.

Ingledew WM. 1999. Alcohol production by Saccharomyces cerevisiae: A yeast primer. In: Lyons TP, Kelsall DR (eds) Nottingham University Press, United Kingdom.

Jacques KA, Lyons TP, Kelsall DR. 2003. The Alcohol Textbook (4thed.). Nottingham University Press, United Kingdom.

Jönsson LJ, Alriksson B, Nilvebrant NO. 2013. Bioconversion of lignocellulose: Inhibitors and detoxification. Biotechnol Biofuels 6 (16): $1-10$.

Kim JH, Block DE, Mills DA. 2010. Simultaneous consumption of pentose and hexose sugars: An optimal microbial phenotype for efficient fermentation of lignocellulosic biomass. Appl Microbiol Biotechnol 88 (5): 1077-1085.

Kofli NT, Dayaon, SHM. 2010. Identification of Microorganism from Ragi for Bioethanol Production by API Kit. J Appl Sci 10 (21): 2751 2753.

Kumar RS, Shankar T, Anandapandian KTK. 2011. Characterization of alcohol-resistant yeast Saccharomyces cerevisiae isolated from Toddy. Int Res J Microbiol 2: 339-405.

Li X, Deng Y, Yang Y, Wei Z, Cheng J, Cao L, Mu D, Luo S, Zheng Z, Jiang S, Wu X. 2017. Fermentation Process and Metabolic Flux of Ethanol Production from the Detoxified Hydrolyzate of Cassava Residue. Front Microbiol 8: 1-12.

Lin Y, Zhang W, Li CJ, Sakakibara K, Tanaka S, Kang HN. 2012. Factors affecting ethanol fermentation using Saccharomyces cerevisiae BY4742. Biomass Bioenergy 47: 395-401.

Lynd LR, Weimer PJ, van Zyl WH, Pretorius IS. 2002. Microbial cellulose utilization: Fundamentals and biotechnology. Microbiol Mol Biol Rev 66: 506-577.

Malherbe S, Cloete TE. 2002. Lignocellulose biodegradation Fundamentals and applications. Rev Environ Sci Biotechnol 1: 105 114.

Merico A, Sulo P, Piskur J, Compagno C. 2007. Fermentative lifestyle in yeasts belonging to the Saccharomyces complex. FEBS J 274: $976-$ 989.

Mohammad S, Awg-Adeni DS, Bujang KB, Vincent M, Baidurah S 2020. Potentials of sago fibre hydrolysate (SFH) as a sole fermentation media for bioethanol production. IOP Conf Ser: Mater Sci Eng 716 (1): 012001. DOI: 10.1088/1757-899x/716/1/012001

Mosier N. 2005. Features of promising technologies for pretreatment of lignocellulosic biomass. Bioresour Technol 96 (6): 673-686.

Narendranath, N. 2003. Bacterial contamination and control in ethanol production. In: Jacques KA, Lyons TP, Kelsall DR (eds) Nottingham University Press, United Kingdom.

Pagliardini J, Hubmann G, Alfenore S, Nevoigt E, Bideaux C, Guillouet SE. 2013. The metabolic costs of improving ethanol yield by reducing glycerol formation capacity under anaerobic conditions in Saccharomyces cerevisiae. Microb Cell Fact 12 (1): 29. DOI: 10.1186/1475-2859-12-29.

Ruriani E, Sunarti TC, Meryandini A. 2012. Yeast isolation for bioethanol production. Hayati 19 (3): 145-149.

Ştefănescu-Mihăilă RO. 2016. Rural economy and bioethanol production. Sustainability 8: 1148. DOI: 10.3390/su8111148.

Techaparin A, Thanonkeo P, Klanrit P. 2017. High-temperature ethanol production using thermotolerant yeast newly isolated from Greater Mekong Subregion. Braz J Microbiol 48 (3): 461-475.

Tsuyoshi N, Fudou R, Yamanaka S, Kozaki M, Tamang N, Thapa S, Tamang JP. 2005. Identification of yeast strains isolated from marcha in Sikkim, a microbial starter for amylolytic fermentation. Int J Food Microbiol 99: 135-146.

Turner SA, Butler G. 2014. The Candida Pathogenic Species Complex. Cold Spring Harb Perspect Med 4 (9). DOI: 10.1101/cshperspect.a019778.

Tye YY, Lee KT, Abdullah WNW, Leh CP. 2011. Second-generation bioethanol as a sustainable energy source in Malaysia transportation sector: Status, potential and future prospects. Renew Sustain Energy Rev 15 (9): 4521-4536.

Vincent M, Senawi BR, Esut E, Muhammad-Nor N, Adeni DS. 2015. Sequential saccharification and simultaneous fermentation (SSSF) of sago hampas for the production of bioethanol. Sains Malays 44 (6): 899-904.

Vincent M, Hung HC, Baran PRM, Azahari AS, Adeni DSA. 2018. Isolation, identification and diversity of oleaginous yeasts from Kuching, Sarawak, Malaysia. Biodiversitas 19 (4): 1266-1272.

Vincent M, Junaidi F, Bilung LM, Suhaili N, Husaini AA, Kanakaraju D. 2020. Simultaneous reclamation of sago starch processing effluent water and Rhizopus oligosporus cultivation at different $\mathrm{pH}$ conditions. J Water Environ Technol 18 (4): 254-263.

Watanabe I, Nakamura T, Shima J. 2010. Strategy for simultaneous saccharification and fermentation using a respiratory-deficient mutant of Candida glabrata for bioethanol production. J Biosci Bioeng 110 (2): 176-179.

Wei CCS, Seng L, Hussaini AASA, Zulkarnain A, Apun K, Bilung L, Vincent M. 2015. Molecular technique identification of the microbial population in palm oil mill effluent (POME). J Oil Palm Res 27 (3): 293-298.

Wong SH, Vincent M. 2019. Development of Rhodotorula mucilaginosa strain via random mutagenesis for improved lipid production. Malays J Microbiol 15 (7): 566-576.

Zhang X, Lei H, Chen S, Wu J. 2016. Catalytic co-pyrolysis of lignocellulosic biomass with polymer: A critical review. Green Chem 18 (15): 4145-4169.

Zhao Y, Lu W, Wang H. 2009. Supercritical hydrolysis of cellulose for oligosaccharide production in combined technology. Chem Eng J 150 (2-3): 411-417. 